\title{
Effect of hydrogen-induced plasticity on the stress corrosion cracking of X70 pipeline steel in simulated soil environments
}

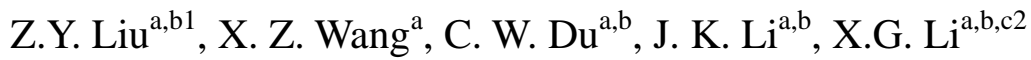 \\ ${ }^{\mathrm{a} C}$ Corrosion and Protection Center, University of Science and Technology Beijing, Beijing, 100083, China \\ ${ }^{\mathrm{b}}$ Key Laboratory of Corrosion and Protection of Ministry of Education,Beijing, 100083, China \\ ${ }^{\mathrm{c}}$ Ningbo Institute of Material Technology \& Engineering, Chinese Academy of Sciences, Ningbo 315201, Zhejiang, \\ China.
}

\begin{abstract}
The susceptibility to stress corrosion cracking (SCC) of X70 pipeline steel under cathodic protection in near-neutral $\mathrm{pH}$ and acidic solutions was investigated by slow-strain-rate tensile test, circumferential-notch tensile (CNT) test, and three-point-bending (TPB) test. Results confirmed the existence of a hydrogen-induced plasticity (HIP) effect within a particular range of cathodic potentials. HIP effect lowered the SCC risk of X70 steel by releasing stress concentration at crack-initiation spots and then decreasing the stress intensity. Crack-growth behavior examined by CNT and TPB tests proved the existence of an HIP effect.
\end{abstract}

Key words: Pipeline steel; Hydrogen induced plasticity; Stress corrosion cracking; Soil environments

\footnotetext{
1 Corresponding authors:

Tel:+86-10-62333931;Fax: +86-10-62334005.E-mail addresses: liuzhiyong7804@ustb.edu.cn (Z.Y. Liu).

2 Corresponding authors:

Tel:+86-10-62333931;Fax: +86-10-62334005.E-mail addresses: lixiaogang99@ustb.edu.cn (X.G. Li).
} 


\section{Introduction}

The stress corrosion cracking (SCC) of pipelines in soil environments have posed significant problems to the petroleum industry over the past decades [1-3]. Two types of SCC, namely, high pH SCC [4-5] $(\mathrm{pH}>9.0)$ and near-neutral $\mathrm{pH}$ [6-10] (at a pH around 6.5), have been identified since the first case of SCC found in the USA. High-pH SCC for pipelines follows the anodic dissolution (AD) mechanism [4,7], whereas low-pH SCC involves the combined effect of hydrogen and non-steady electrochemical effect on dissolution of the steel [6-10]. Parkins et al. [10] concluded that near-neutral $\mathrm{pH}$ SCC results from the cooperation of anodic dissolution and the effect of hydrogen in the steel. Beavers [11] pointed out that SCC is initiated by anodic dissolution (AD), and its propagation is driven by hydrogen-induced cracking (HIC). Cheng et al. [12-13] quantified the contributions of stress, hydrogen, and their synergism to dissolution of steel at the crack tip, i.e., hydrogen-induced dissolution, in near-neutral pH solution. Hydrogen evolution is responsible for SCC of pipeline steels. However, Lu et al. [1,9] reported that hydrogen has limited effect on active dissolution of pipeline steel in near-neutral $\mathrm{pH}$ underground water. These results imply that the relationship between the effect of hydrogen and anodic dissolution has not been fully identified. More recently, Liu et al. [14-19] have extensively studied the SCC mechanism of pipe steels, including X70, X80, and X100 steels, in soil environments. They demonstrated that the different electrochemical statuses between the crack tip and the crack wall give rise to a combined effect of hydrogen. Moreover, both high-pH SCC and near-neutral pH SCC are strongly related to cathodic potential 
(CP). The SCC of pipeline steels is under the combined effect of AD and HE When the applied $\mathrm{CP}$ is about between $-730 \mathrm{mV}_{\mathrm{SCE}}$ and $-920 \mathrm{mV}_{\mathrm{SCE}}$ in near neutral solution. The SCC susceptibility increases first and then decreases with the negative shift of CP. However, SCC susceptibility increases again when the applied potential is more negative than $-920 \mathrm{mV}_{\mathrm{SCE}}$ [14]. This finding introduces a big challenge for the security of pipelines on protecting the steel sufficiently and lowering the risk of SCC at the same time. On one hand, hydrogen evolution is intensified when CP-on, which is believed as one of the main reasons of SCC. On the other hand, hydrogen may have an important effect in metal matrix, i.e., hydrogen-induced plasticity (HIP) [20-22] other than hydrogen embrittlement, on mechanical and SCC properties. HIP decreases the stress intensity at the crack tip and lowers the SCC risk of pipeline steels by releasing the stress concentration at SCC initiation spots and enlarging deformation zone in front of the crack tip, thereby providing a possibility to optimize the $\mathrm{CP}$ condition. However, the detailed mechanism of HIP and its relationship with SCC under CP remain unclear and need further investigation.

In this work, slow-strain-rate tensile (SSRT) tests were performed on API X70 pipeline steel to confirm an effective CP range of HIP with low SCC susceptibility. The mechanism of HIP was investigated by circumferential-notch tensile (CNT) test and three-point-bending (TPB) test.

\section{Experimental}

All samples used in this work were made of X70 pipeline steel supplied by 
Baosteel Co., Ltd., China, with the following chemical composition (wt.\%): $0.065 \mathrm{C}$, 0.23 Si, $1.57 \mathrm{Mn}, 0.056 \mathrm{Nb}, 0.20 \mathrm{Ni}, 0.18 \mathrm{Cr}, 0.22 \mathrm{Cu}, 0.027 \mathrm{Al}, 0.015 \mathrm{Ti}, 0.028 \mathrm{~V}$, $0.0020 \mathrm{~S}$, and $0.0019 \mathrm{P}$ and Fe balance.

The solutions used include a near-neutral $\mathrm{pH}$ solution, i.e., NS4 solution, to simulate the electrolyte trapped under disbanded coating in Canada [18] and an acidic solution with $\mathrm{pH} \approx 4$ to simulate an acidic soil located in southeast China [23]. The chemical contents of these two solutions are listed in Table 1. Both solutions were produced from analytical grade reagents and ultra-pure water. Prior to the tests, the NS4 solution was purged with $5 \% \mathrm{CO}_{2}$ balanced with $\mathrm{N}_{2}$ gas for $1 \mathrm{~h}$ to achieve an anaerobic and near-neutral $\mathrm{pH}$ condition, with a $\mathrm{pH}$ of approximately 6.3. The $\mathrm{pH}$ of the acidic solution was adjusted to 4.0 by adding acetic acid; pure nitrogen gas was purged to the solution to remove oxygen before tests. The gas flows of the two solutions were maintained throughout the tests.

The SSRT test was performed at a strain rate of $1 \times 10^{-6} \mathrm{~s}^{-1}$ in air and in the two testing solutions at various CPs through a WDML-30KN Materials Test System. Two types of SSRT samples were used: those for the test in NS4 were cut with the tensile direction parallel to the rolling direction, while those for examination in the $\mathrm{pH} 4$-solution were machined with the loading direction of $45^{\circ}$ to the rolling direction. The tensile specimens were ground sequentially to 1500 grit emery papers, with the grounding direction parallel to the applied stress.

The specimen was pre-immersed in the solution under the designed cathodic potential or open circuit potential for $24 \mathrm{~h}$ before the SSRT test. Each test was 
repeated three times to ensure the reproducibility of the results. ${ }^{[24]}$ After the SSRT tests, the specimens were immersed into a descaled solution $(500 \mathrm{~mL} \mathrm{HCl}+500 \mathrm{~mL}$ $\left.\mathrm{H}_{2} \mathrm{O}+3.5 \mathrm{~g}\left(\mathrm{CH}_{2}\right)_{6} \mathrm{~N}_{4}\right)$ in an ultrasonic container for $3 \mathrm{~min}$, degreased with acetone, and dried with cool air. Surface morphologies were observed by scanning electron microscopy (SEM).

The crack growth property of the X70 steel was characterized by CNT and TPB tests. The dimensions of the CNT and TPB specimens are shown in Fig. 1. The compact tensile specimen was immersed in NS4 solution and loaded a stress of $0.625 \mathrm{R}$ ratio cyclically with the frequency of $0.002 \mathrm{~Hz}$. The maximum stress was controlled to achieve a maximum stress intensity factor $\left(K_{\max }\right)$ within the range of $77 \mathrm{MPa} \sqrt{\mathrm{m}}$ to $104 \mathrm{MPa} \sqrt{\mathrm{m}}$, and the stress intensity factor $(\Delta K)$ ranged from $29 \mathrm{MPa} \sqrt{\mathrm{m}}$ to $39 \mathrm{MPa} \sqrt{\mathrm{m}}$. The TPB specimen was loaded at a rate of $0.002 \mathrm{~mm} \cdot \mathrm{min}^{-1}$ in the $\mathrm{pH} 4$ acidic synthetic soil solution. The loading cycle and test time were systematically documented by a computer. Crack growth was observed and monitored using a microscope equipped with a charge-coupled device camera system as described previously [25]; the crack growth length was measured every few hours.

Potentiodynamic polarization curves were measured in an electrochemical three-electrode cell, with the X70 steel specimen as working electrode, saturated calomel electrode (SCE) as reference electrode, and platinum plate as counter electrode.

All tests were performed at ambient temperature (about $22{ }^{\circ} \mathrm{C}$ ). 


\section{Results}

The stress-strain curves of the X70 steel measured in air and different testing solutions at $-850 \mathrm{mV}_{\mathrm{SCE}}$ are shown in Fig. 2. The elongation of the steel decreased in both NS4 and acidic solutions compared with that obtained in air, indicating that the $\mathrm{X} 70$ steel is susceptible to SCC in these two solutions.

Fig. 3 shows the stress-strain curves of the X70 steel in the NS4 and acidic solutions under various polarizing potentials. The elongation and ultimate tensile strength of the steel exhibited complex dependence on the CPs. To investigate the SCC susceptibility of steel in soil solutions, the ratio of reduction in elongation $I_{\eta}$ and the ratio of reduction in area $I_{\Psi}$ were calculated by Eqs. (1) and (2):

$$
\begin{aligned}
& I_{\eta}=\left(1-\frac{\eta_{E}}{\eta_{0}}\right) \times 100 \% \\
& I_{\Psi}=\left(1-\frac{\psi_{E}}{\psi_{0}}\right) \times 100 \%
\end{aligned}
$$

where $\eta_{0}$ and $\eta_{E}$ are the reduction-in-elongation in air and in the solution at various potentials, respectively, and $\Psi_{0}$ and $\Psi_{E}$ are the reduction-in-area measured in air and in the solution at various potentials, respectively. Fig. $\mathbf{4}$ and $\mathbf{5}$ show the calculated $I_{\eta}$ and $I_{\Psi}$ values. Larger $I_{\eta}$ and $I_{\psi}$ values correspond with higher susceptibility to SCC. Fig. 4 shows that $I_{\eta}$ decreases first with the negative shift of potential in the range of $-750 \mathrm{mV}_{\mathrm{SCE}}$ to $-930 \mathrm{mV}_{\mathrm{SCE}}$, and then increases as the applied potential negatively shifts further. Therefore, a particular CP range exists, in which the specimens display lower SCC susceptibility, compared with the results at more negative or positive potential conditions. Fig. 5 shows that $I_{\Psi}$ increases with the negative shift of potential in the range of $-730 \mathrm{mV}_{\mathrm{SCE}}$ to $-890 \mathrm{mV}_{\mathrm{SCE}}$, then decreases significantly in the 
potential range of $-890 \mathrm{mV}_{\mathrm{SCE}}$ to $-920 \mathrm{mV}_{\mathrm{SCE}}$, and finally increases again when the applied potential is more negative than $-920 \mathrm{mV}_{\mathrm{SCE}}$. This finding exhibits the similar changing rules in the $\mathrm{pH} 4$ acidic solution with slight differences in potential transfer range. This phenomenon is related to the electrochemical behavior of the steel in these two solutions under cathodic potential. According to the non-equilibrium electrochemical theory proposed in our previous work ${ }^{[14,15]}$, anodic dissolution could occur on the polarized steel under the applied potential between two null-current potentials on the polarization curves with slow and fast scanning rates. Therefore, a peak potential is observed under which the steel exhibits the maximum SCC susceptibility. In addition, the difference of the peak potential in the two kinds of solutions is attributed to the discrepancy of the potential range under which both anodic dissolution and hydrogen evolution occur ${ }^{[14,15]}$.

To characterize the relationship of SCC initiation with applied potentials, the micro-cracks on the side surface of the SSRT samples were observed by SEM and shown in Fig. 6. The SCC initiation density is strongly related to the potential conditions. Large-scale, discontinuous, small cracks were observed for the X70 steel in $\mathrm{pH} 4$ solution at $-750 \mathrm{mV}_{\mathrm{SCE}}$. A certain number of cracks connected together in the central areas with the application of $-850 \mathrm{mV}_{\mathrm{SCE}} \mathrm{CP}$; hence, longer cracks were detected. However, visible cracks became scarce and only slight SCC occurred on the side surface with further negative shift of $\mathrm{CP}$ to $-950 \mathrm{mV}_{\mathrm{SCE}}$, indicating that the steel exhibited better SCC resistance at $-950 \mathrm{mV}_{\text {SCE}}$. The statistics of crack densities are shown in Fig. 7, wherein the largest crack appeared at $-750 \mathrm{mV}_{\mathrm{SCE}}$, whereas became 
smaller at $-850 \mathrm{mV}_{\mathrm{SCE}}$ because of crack connection. The crack number sharply dropped to $30 / \mathrm{cm}^{2}$, which was approximately $25 \%$ of that at $-750 \mathrm{mV}_{\mathrm{SCE}}$, when the potential negatively shifted to $-950 \mathrm{mV}_{\mathrm{SCE}}$.

The SCC crack depth on the fracture surface is observed and the maximum crack depth is measured. Fig. 8 shows the method to measure the maximum crack depth, while the statistic results of the maximum crack depth at different potentials are shown in Fig. 9. The maximum crack depth results are consistent with the results of $I_{\Psi}$ in Fig. 5. In the pH 4 acidic solution, the maximum crack depth significantly increased when the potential shifted negatively from $-680 \mathrm{mV}_{\mathrm{SCE}}$ to $-980 \mathrm{mV}_{\mathrm{SCE}}$; a sharp drop was observed at $-1050 \mathrm{mV}_{\mathrm{SCE}}$. When the applied potential shifted further to $-1200 \mathrm{mV}_{\mathrm{SCE}}$, the maximum crack depth increased again. For the specimen in the NS4 solution, the change rule of maximum crack depth exhibited a similar pattern to that in the $\mathrm{pH} 4$ solution, except for the transfer potential at which the maximum crack depth started to decrease.

Given that hydrogen evolution is the primary cathodic reaction that occurs in anaerobic NS4 and acidic solutions [14], the cathodic current density has a strong relationship with hydrogen concentration. The hydrogen content in the steel has a significant effect on the SCC process. Thus, both SCC susceptibility index and cathodic current density must be considered to accurately discuss the role of hydrogen inside the steel on the SCC process, as shown in Fig. 10. A critical amount of hydrogen was observed; however, the exact amount cannot be determined, which affects the index, as marked with a dotted line in the figure. When the hydrogen 
content inside steel is insufficient, hydrogen indirectly affects SCC susceptibility, while other influencing factors are supposed to be working as well. When the hydrogen content reaches above the threshold value, a HIC or HE effect will show $u^{[18]}$. Given that the hydrogen evolution is enhanced with the cathodic current density, the HE effect is believed to dominate the SCC growth and dissolution would accelerate the cracking process.

Fig. 11 shows the curves of the crack growth length increase with increased cycle number (loading frequency $\mathrm{f}=0.002 \mathrm{~Hz}$ ) or test time at varying applied potentials. Crack growth was faster at $-1200 \mathrm{mV}_{\mathrm{SCE}}$ in both tests than that at $-850 \mathrm{mV}_{\mathrm{SCE}}$ and OCP. However, the results at $-850 \mathrm{mV}_{\mathrm{SCE}}$ and $\mathrm{OCP}$ were different, indicating that loading modes (cycle loading and continuous loading) have certain effect on growth behavior. For CNT specimen under cycle loading, the crack growth is much slower at $-850 \mathrm{mV}_{\mathrm{SCE}}$ than that at $\mathrm{OCP}$, while the opposite result is obtained for the TPB specimen under continuous loading.

\section{Discussion}

4.1 Analysis of the electrochemical reactions for pipeline steels in simulated soil environments and its relationship with the SCC process.

The anodic reaction of the X70 steel in the testing solutions is the oxidation of iron [26].

$$
\mathrm{Fe} \rightarrow \mathrm{Fe}^{2+}+2 \mathrm{e}
$$

The cathodic reaction of the steel includes reduction of $\mathrm{H}^{+}, \mathrm{HCO}_{3}{ }^{-}, \mathrm{H}_{2} \mathrm{CO}_{3}$, and $\mathrm{H}_{2} \mathrm{O}$ : 


$$
\begin{aligned}
& 2 \mathrm{H}^{+}+2 \mathrm{e} \leftrightarrow \mathrm{H}_{2} \\
& 2 \mathrm{H}_{2} \mathrm{CO}_{3}+2 \mathrm{e} \leftrightarrow \mathrm{H}_{2}+2 \mathrm{HCO}_{3}^{-} \\
& 2 \mathrm{HCO}_{3}^{-}+2 \mathrm{e} \leftrightarrow \mathrm{H}_{2}+2 \mathrm{CO}_{3}^{2-} \\
& 2 \mathrm{H}_{2} \mathrm{O}+2 \mathrm{e} \leftrightarrow \mathrm{H}_{2}+2 \mathrm{OH}^{-}
\end{aligned}
$$

The corrosion product, a layer of porous $\mathrm{Fe}(\mathrm{OH})_{2}$, is formed on the steel surface with the increase in anodic and cathodic reactions:

$$
\mathrm{Fe}^{2+}+2 \mathrm{OH}^{-} \leftrightarrow \mathrm{Fe}(\mathrm{OH})_{2}
$$

Compared with the cathodic reactions in the NS4 solution, the hydrogen evolution process in the $\mathrm{pH} 4$ acidic solution is accelerated based on the fact that the hydrogen ion concentration is much higher, as shown in Fig. 10. In the SCC process, fresh matrix surface at crack tip is continuously generated because of tensile stress on the specimen, resulting in an unstable or non-equilibrium electrochemical status at the crack tip. Meanwhile, the crack wall is covered with a corrosion product layer or equilibrium electric double layer, under which electrochemical reactions take place in a quasi-equilibrium state. The anodic dissolution reaction (3) and the cathodic hydrogen evolution reactions (4), (5), and (6) at the crack tip are promoted. As a result, the different electrochemical states between the crack tip and crack wall introduce a combined effect of hydrogen embrittlement and anodic dissolution on the occurrence of SCC, which leads to high SCC susceptibility when the applied potential is between OCP and $-950 \mathrm{mV}_{\mathrm{SCE}}[14]$.

\subsection{HIP and its effect on the SCC process}

Two SCC susceptibility factors, namely, ratio of reduction-in-elongation $I_{\eta}$ and 
ratio of reduction-in-area $I_{\Psi}$, were widely used to characterize the SCC susceptibility of the pipeline steels. Generally, $I_{\Psi}$, which reflects the sensitivity of SCC at the stage of crack propagation is mainly affected by cracks and defects inside the steel. Thus, maximum crack depth statistic results in Fig. 9 and the side surface crack initiation behavior shown in Fig. 6 are consistent with the results of $I_{\Psi}$ in Fig. 5 because they are all influenced by the same material factors. Meanwhile, $I_{\eta}$, which mainly characterizes the dislocation and deformation of a specimen, is influenced by hydrogen content inside the steel [27].

The CP applied to the operating pipelines will protect the steel from corrosion with the presence of coating defects by penetrating the coating and reaching the steel surface. However, anodic dissolution will still occur and contribute to the SCC process even when the pipeline is under cathodic protection [14], which challenges the cathodic protection effectiveness. This work demonstrates an effective $\mathrm{CP}$ range of HIP with low SCC susceptibility for pipeline steels. As shown in Figs. 4 and 10, an HIP effect is confirmed in the potential range between $-680 \mathrm{mV}_{\mathrm{SCE}}$ and $-930 \mathrm{mV}_{\mathrm{SCE}}$. Within this potential range, the HIP effect postpones the initiation process of SCC and lowers the growth rate of cracks to slow down the propagation process by releasing the stress concentration at the crack initiation regions and enlarging the deformation zone in front of the crack tip. In other words, HIP effect within this potential range lowers the SCC risk of the pipeline steels.

The results of the crack growth test also display the influence of HIP effect on SCC behavior. For the compact tensile specimen under non-continuous loading mode, 
crack opening angle cyclically opens and contracts and the hydrogen at the crack tip could loosen the load on the specimen and decrease the stress concentration, consequently prohibiting crack growth when the hydrogen content inside the steel is below the critical amount. However, for the TPB specimen under continuous loading, crack opening angle continuously increases and fresh crack tip shows up continuously because of the stress effect; hence, the cracks grow continuously. For the cycle loading specimen at $\mathrm{CP}$ of $-850 \mathrm{mV}$, crack grows much slower than that under OCP. More hydrogen will be generated as the specimen is under more negative $\mathrm{CP}$ than that at OCP. A hydrogen embrittlement effect, which could accelerate crack growth, is expected to appear. However, a HIP phenomenon may also play a role during this SCC process. HIP releases the stress concentration around the crack tip, decreases the stress intensity of SCC, and then prohibits crack growth to some extent, consistent with the results in Fig. 4. Therefore, the crack growth of the CNT specimen is much slower at $-850 \mathrm{mV}_{\mathrm{SCE}}$ than that at OCP, while the result obtained by TPB specimen under continuous loading is opposite, as seen in Fig.11.

\section{Conclusion}

A high SCC susceptibility potential range (owing to the non-steady electrochemical effects) and an HIP potential range exist between $\mathrm{OCP}$ and $-950 \mathrm{mV}_{\mathrm{SCE}} \mathrm{CPs}$ for pipeline steel under CP. The HIP phenomenon postpones the initiation and the propagation of SCC when the applied potential is within the high SCC susceptibility potential range. This positive effect of HIP would reduce the risk 
of SCC in the corresponding potential ranges.

\section{Acknowledgements}

This work was supported by National Basic Research Program of China (973 Program) (No. 2014CB643300) and the Chinese National Science Foundation (Nos. 51131001 and 51471034).

\section{References}

[1] B.T. Lu, J.L. Luo, P.R. Norton, Environmentally assisted cracking mechanism of pipeline steel in near-neutral pH groundwater, Corros. Sci. 52 (2010) 1787-1795.

[2] B. Saleem, F. Ahmed, M. A.Rafiq, et al., Stress corrosion failure of an X52 grade gas pipeline, Eng. Fail. Anal. 46 (2014) 157-165.

[3] M. S. Yu, X. Xing, H. Zhang, et al., Corrosion fatigue crack growth behavior of pipeline steel under load-type variable amplitude loading schemes, Acta Mater. 96 (2015) 159-169.

[4] A.A. Oskuie, T. Shahrabi, A. Shahriari, et al., Electrochemical impedance spectroscopy analysis of X70 pipeline steel stresscorrosion cracking in high $\mathrm{pH}$ carbonate solution, Corros. Sci. 61 (2012) 111-122.

[5] S. Bordbar, M. Alizadeh, S. H.Hashemi, Effects of microstructure alteration on corrosion behavior of welded jointin API X70 pipeline steel, Mater. Des. 45 (2013) 597-604.

[6] L.Y. Xu, Y.F. Cheng, An experimental investigation of corrosion of X100 
pipeline steel under uniaxial elastic stress in a near-neutral $\mathrm{pH}$ solution, Corros. Sci. 59 (2012) 103-109.

[7] B.T. Lu, F. Song, M. Gao, et al., Crack growth model for pipelines exposed to concentrated carbonate-bicarbonate solution with high pH, Corros. Sci. 52 (2010) 4064-4072.

[8] A. Eslami, R. Kania, B. Worthingham, et al., Effect of $\mathrm{CO}_{2}$ and R-ratio on near-neutral $\mathrm{pH}$ stress corrosion cracking initiation under a disbonded coating of pipeline steel, Corros. Sci. 53 (2011) 2318-2327.

[9] B.T. Lu, J.L. Luo, P.R. Norton, et al., Effects of dissolved hydrogen and elastic and plastic deformationon active dissolution of pipeline steel in anaerobic groundwaterof near-neutral pH, Acta Mater. 57 (2009) 41-49.

[10]R.N. Parkins, W.K. Blanchard Jr., B.S. Delanty, Transgranular stress corrosion cracking of high pressure pipelines in contact with solutions of near neutral $\mathrm{pH}$, Corrosion 50 (1994) 394-408.

[11]J. A. Beavers,B. A. Harle, Mechanism of high-pH and near-neutral-pH SCC of underground pipelines, J Offshore Mech. Arct. 123 (2001) 147-151.

[12]G.A. Zhang, Y.F. Cheng, Micro-electrochemical characterization of corrosion of welded X70 pipeline steelin near-neutral pH solution, Corros. Sci. 51 (2009) $1714-1724$

[13]X.Tang, Y.F.Cheng, Quantitative characterization by micro-electrochemical measurementsof the synergism of hydrogen, stress and dissolution on near-neutral pHstress corrosion cracking of pipelines, Corros. Sci. 53 (2011) 
2927-2933.

[14]Z.Y. Liu, X.G. Li, Y.F. Cheng, Mechanistic aspect of near-neutral pH stress corrosion cracking of pipelines under cathodic polarization, Corros. Sci. 55 (2012) 54-60.

[15]Z.Y. Liu, L. Lu, Y.Z. Huang, et al., Mechanistic aspect of non-steady electrochemical characteristic during stress corrosion cracking of an X70 pipeline steel in simulated underground water, Corrosion 70 (2014)678-684.

[16]Z.Y. Liu, X.G. Li, Y.F. Cheng, In-situ characterization of the electrochemistry of grain and grain boundary of anX70 steel in a near-neutral pH solution, Electrochem. Commun. 12 (2010) 936-938.

[17]Z.Y. Liu, X.G. Li, C.W. Du, et al., Local additional potential model for effect of strain rate on SCC of pipeline steel in an acidic soil solution, Corros. Sci. 51 (2009) 2863-2871.

[18]Z.Y. Liu, X.G. Li, C.W. Du, et al., Stress corrosion cracking behavior of X70 pipe steel in an acidic soil environment, Corros. Sci. 50 (2008) 2251-2257.

[19]Z.Y. Liu, Z. Y. Cui, X.G. Li, et al., Mechanistic aspect of stress corrosion cracking of X80 pipeline steel under non-stable cathodic polarization, Electrochem. Commun. 48 (2014) 127-129.

[20]Y.Murakami, T.Kanezaki, Y.Mine, Hydrogen Effect against hydrogen embrittlement, Metall. Mater. Trans. A 41A (2010) 2548-2562.

[21]R. Miresmaeili, L. Liu, H. Kanayama, A possible explanation for the contradictory results of hydrogen effects on macroscopic deformation, Inter. J. 
Pres. Ves. Pip. 99-100 (2012) 34-43.

[22]X.C. Ren, W.Y. Chu, Y.J. Su, et al., The effects of atomic hydrogen and flake on mechanical properties of a tyre steel, Mater. Sci. Eng. A 491 (2008) 164-171.

[23]Z.Y. Liu, C.W. Du, X. Zhang, et al., Effect of $\mathrm{pH}$ value on stress corrosion cracking of x70 pipeline steel in acidic soil environment. Acta Metall. Sinica (English Letters) 26(2013) 489-496.

[24]Chinese National Standard for Stress Corrosion Cracking Tests, GB T15970, 2007.

[25]X.Z. Wang, Z.Y. Liu, X. Ge, et al., Growth Behavior of Stress Corrosion Cracks of X80 Pipeline Steel in Underground Water of Acidic Soil, Corrosion 70 (2014) 872-879.

[26] G.Z. Meng, C. Zhang, Y.F. Cheng, Effects of corrosion product deposit on the subsequent cathodic and anodic reactions of X70 steel in near-neutral pH solution, Corros. Sci. 50 (2008) 3116-3122.

[27]D. Hardie, E.A. Charles, A.H. Lopez, Hydrogen embrittlement of high strength pipeline steels, Corros. Sci. 48 (2006) 4378-4385. 


\section{Figure caption:}

Fig.1. Schematic of the dimensions of compact tensile specimen (a) and three-point-bending specimen (b), units: mm.

Fig.2. Stress-strain curves of $\mathrm{X} 70$ steel measured in air and in testing solutions at $-850 \mathrm{mV} \mathrm{SCE}_{\text {SC }}$.

Fig.3. Stress-strain curves of X70 steel under cathodic protection in NS4 solution (a) and $\mathrm{pH}=4$ solution (b) under various cathodic polarization potentials.

Fig.4. Effect of cathodic potential on the ratio of reduction-in-elongation $\left(I_{\eta}\right)$ in NS4 solution and $\mathrm{pH}=4$ solution.

Fig.5. Effect of cathodic potential on the ratio of reduction-in-area $\left(I_{\psi}\right)$ in NS4 solution and pH=4 solution.

Fig.6. Location of micro-cracks on side surfaces of $\mathrm{X} 70$ steels $\mathrm{pH}=4$ acidic solution at different applied potentials: (a)-750mV; (b)-850mV; (c) $-950 \mathrm{mV}$.

Fig.7. Statistics of crack densities on side surfaces of $\mathrm{X} 70$ samples in $\mathrm{pH}=4$ acidic solution at different applied potentials.

Fig.8. SEM images of fractographies for measuring the maximum crack depth.

Fig.9. Statistic results of maximum crack depth at different potentials.

Fig.10. Dependence of reduction-in-area and corrosion current density obtained in NS4 solution (a) and $\mathrm{pH}=4$ solution (b) on the applied cathodic potentials. 
(a)

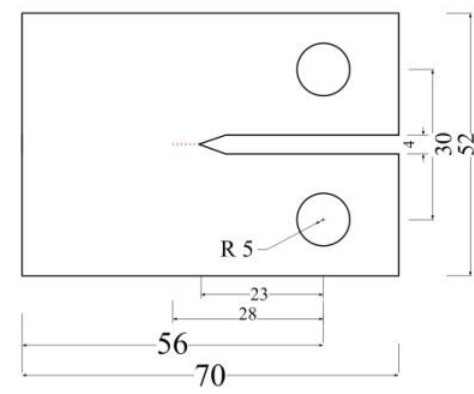

(b)

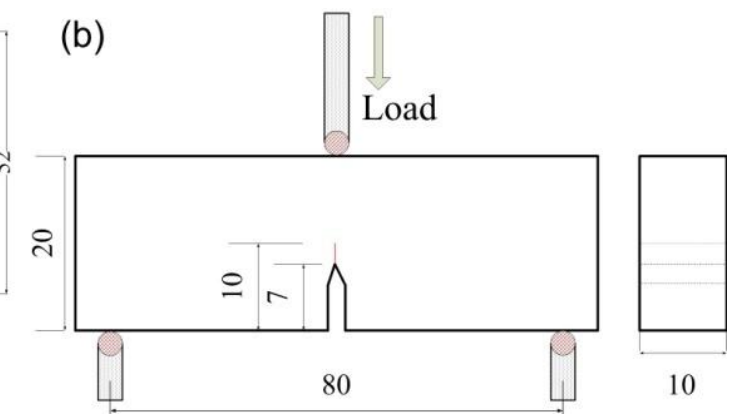

Fig.1. Schematic of the dimensions of compact tensile specimen (a) and three-point-bending specimen (b), units: $\mathrm{mm}$. 


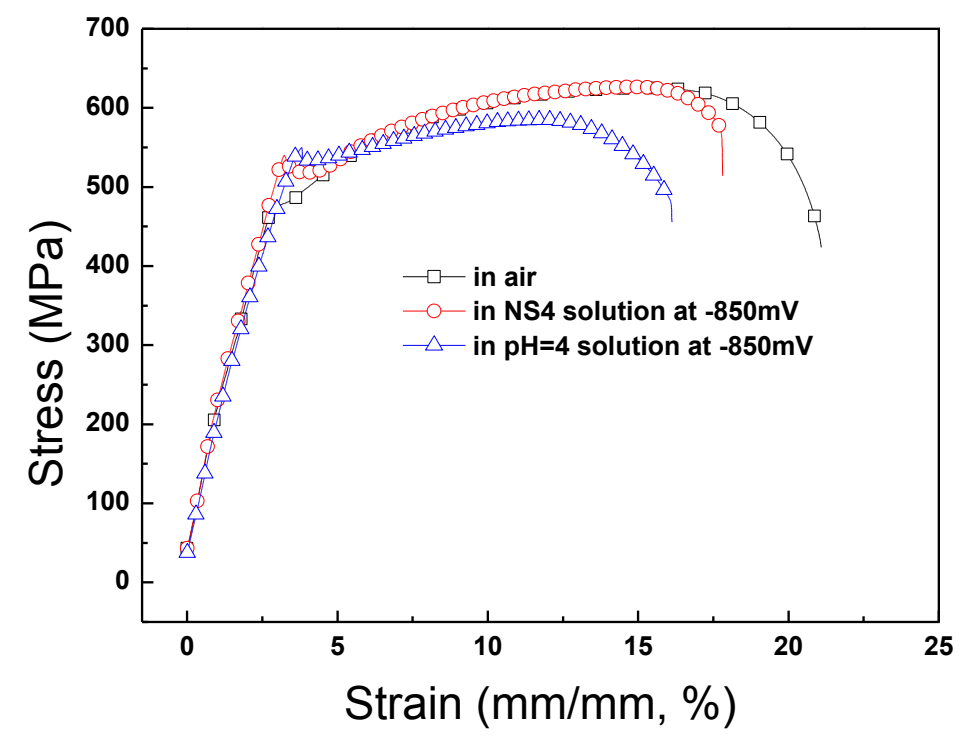

Fig.2 Stress-strain curves of $\mathrm{X} 70$ steel measured in air and in testing solutions at $-850 \mathrm{mV}_{\text {SCE}}$. 

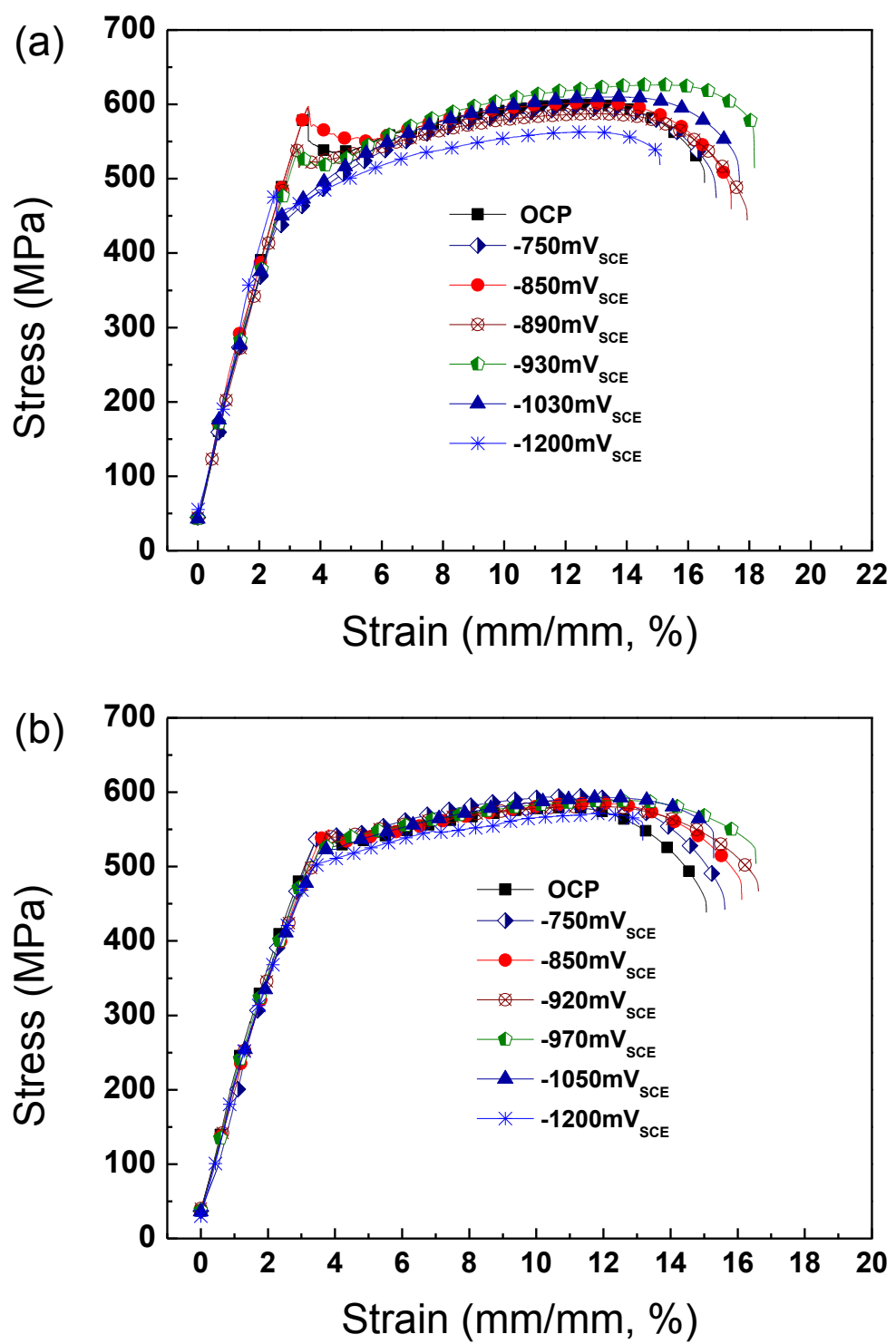

Fig.3Stress-strain curves of X70 steel under cathodic protection in NS4 solution (a)and $\mathrm{pH}=4$ solution (b) under various cathodic polarization potentials. 


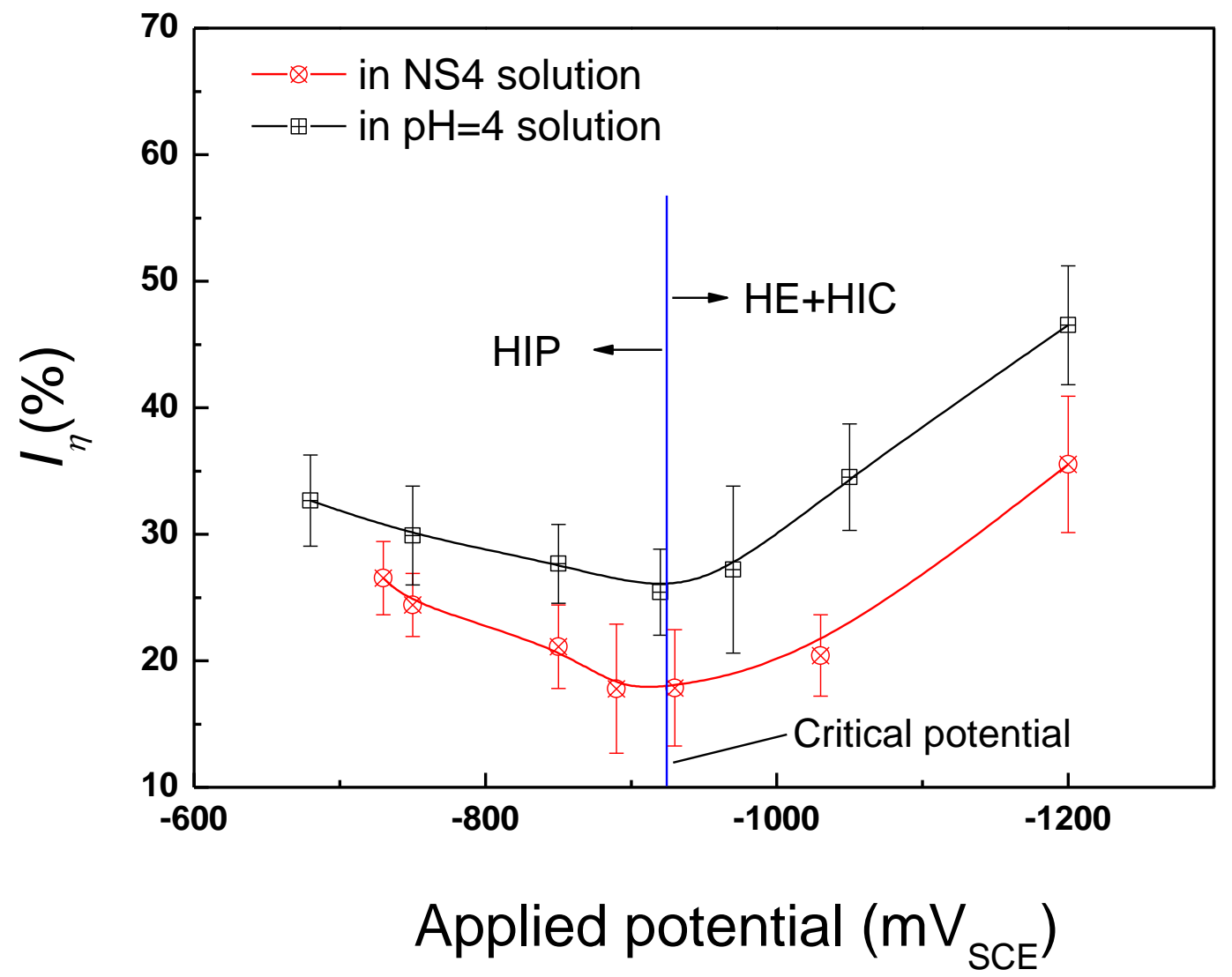

Fig.4. Effect of cathodic potential on the ratio of reduction-in-elongation $\left(I_{\eta}\right)$ in NS4 solution and $\mathrm{pH}=4$ solution. 


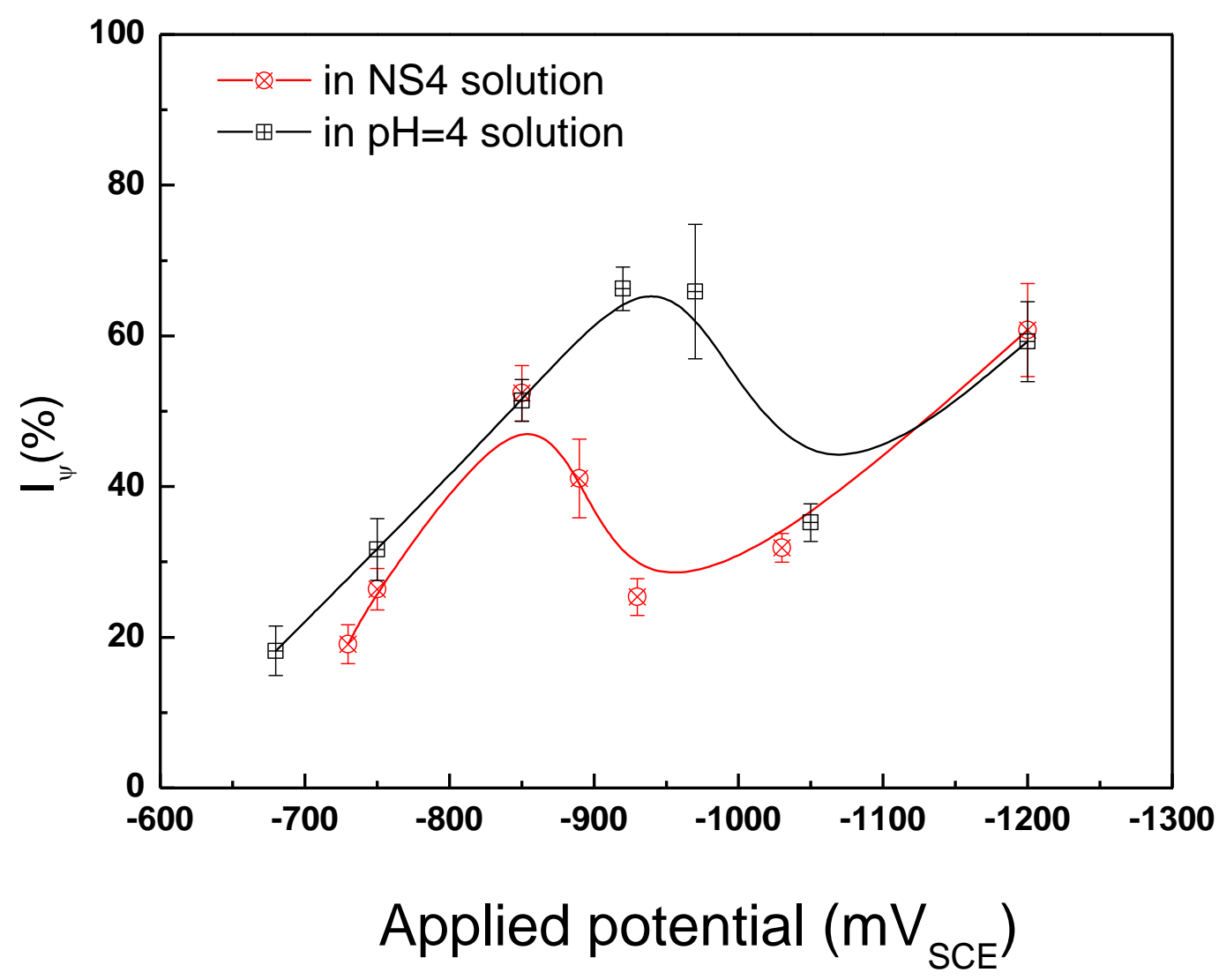

Fig.5. Effect of cathodic potential on the ratio of reduction-in-area $\left(I_{\psi}\right)$ in NS4 solution and $\mathrm{pH}=4$ solution. 

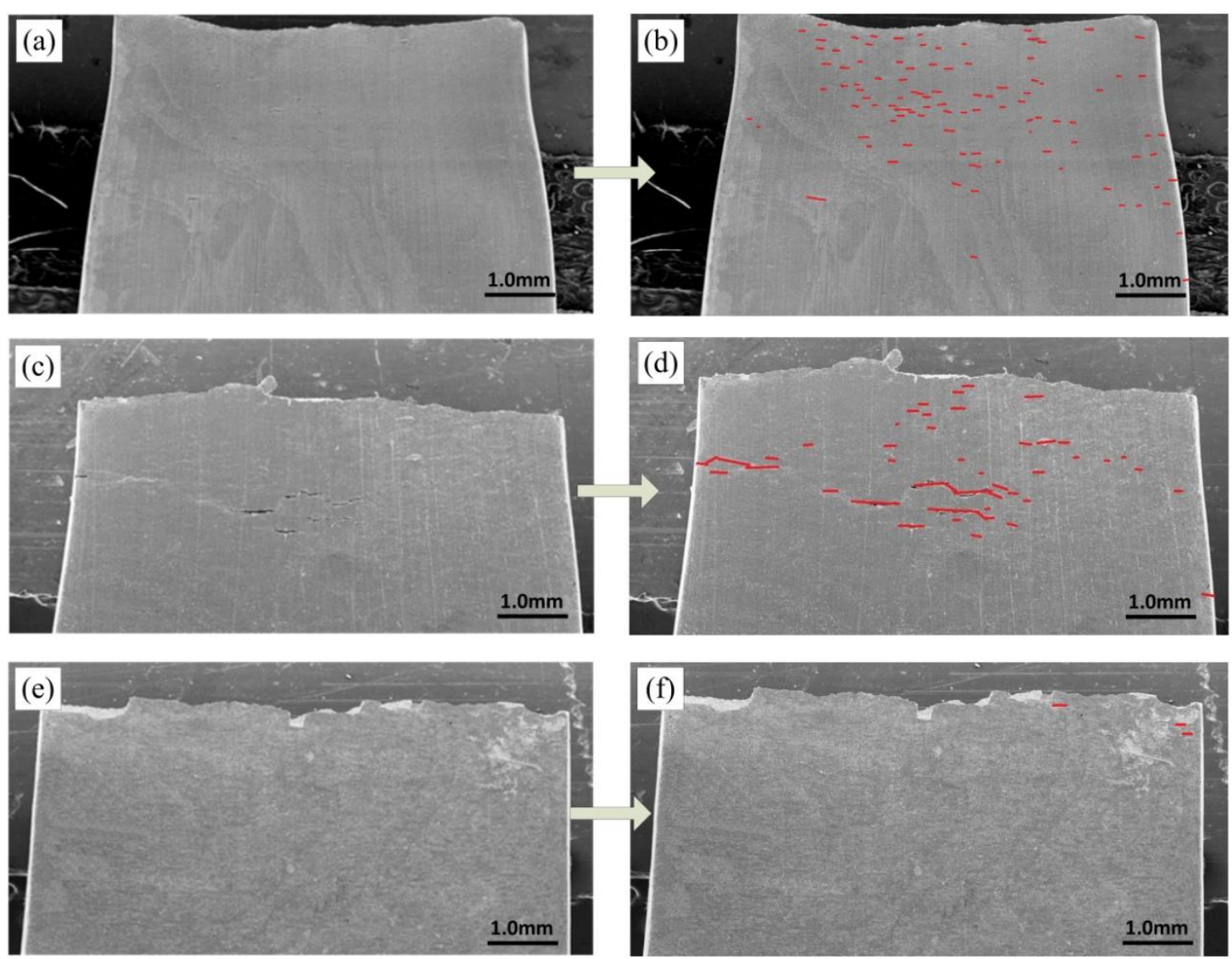

Fig.6. Morphology (a, c, and e) and location (b, d and f) of the micro-cracks on the side surface of the X70 pipeline steel fractured under applied potentials of $-750 \mathrm{mV}$ ( $\mathrm{a}$ and b), $-850 \mathrm{mV}$ (c and d), and $-950 \mathrm{mV}$ (e and f). 


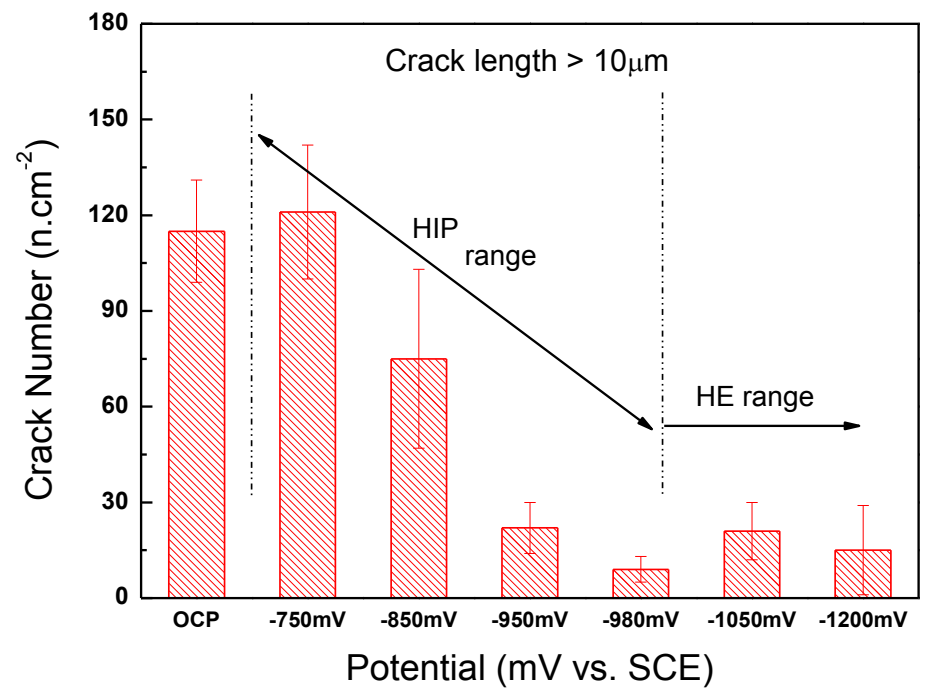

Fig.7.Statistics of crack densities on side surfaces of $\mathrm{X} 70$ samples in $\mathrm{pH}=4$ acidic solution at different applied potentials. 


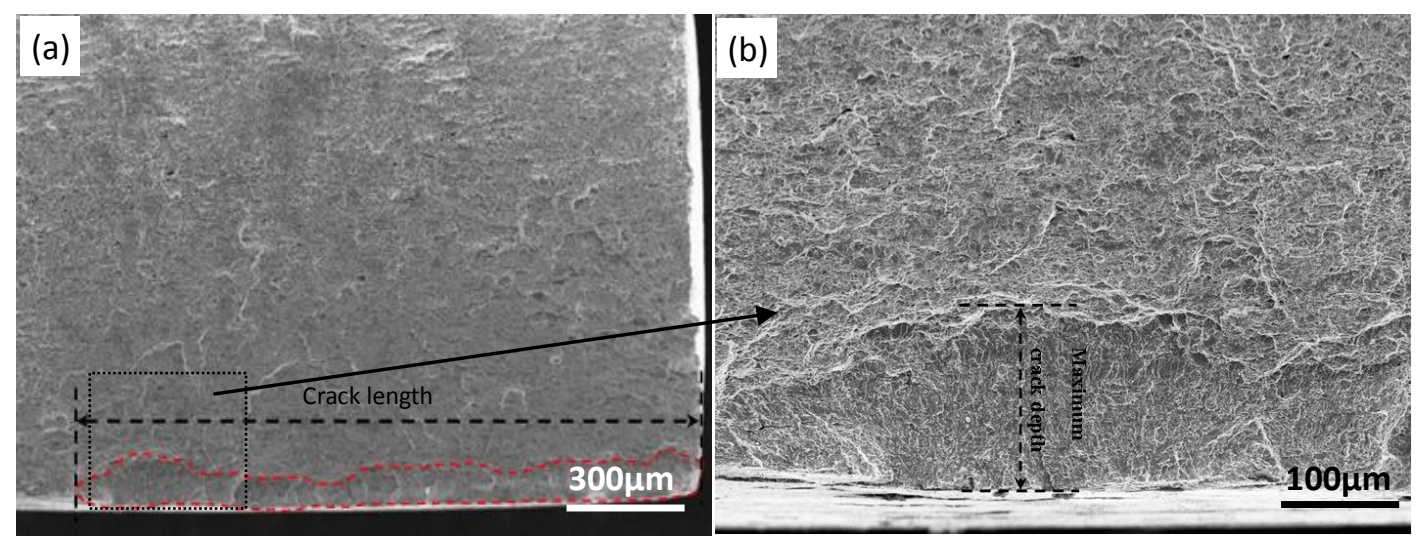

Fig.8. SEM images of fractographies for measuring the maximum crack depth. 


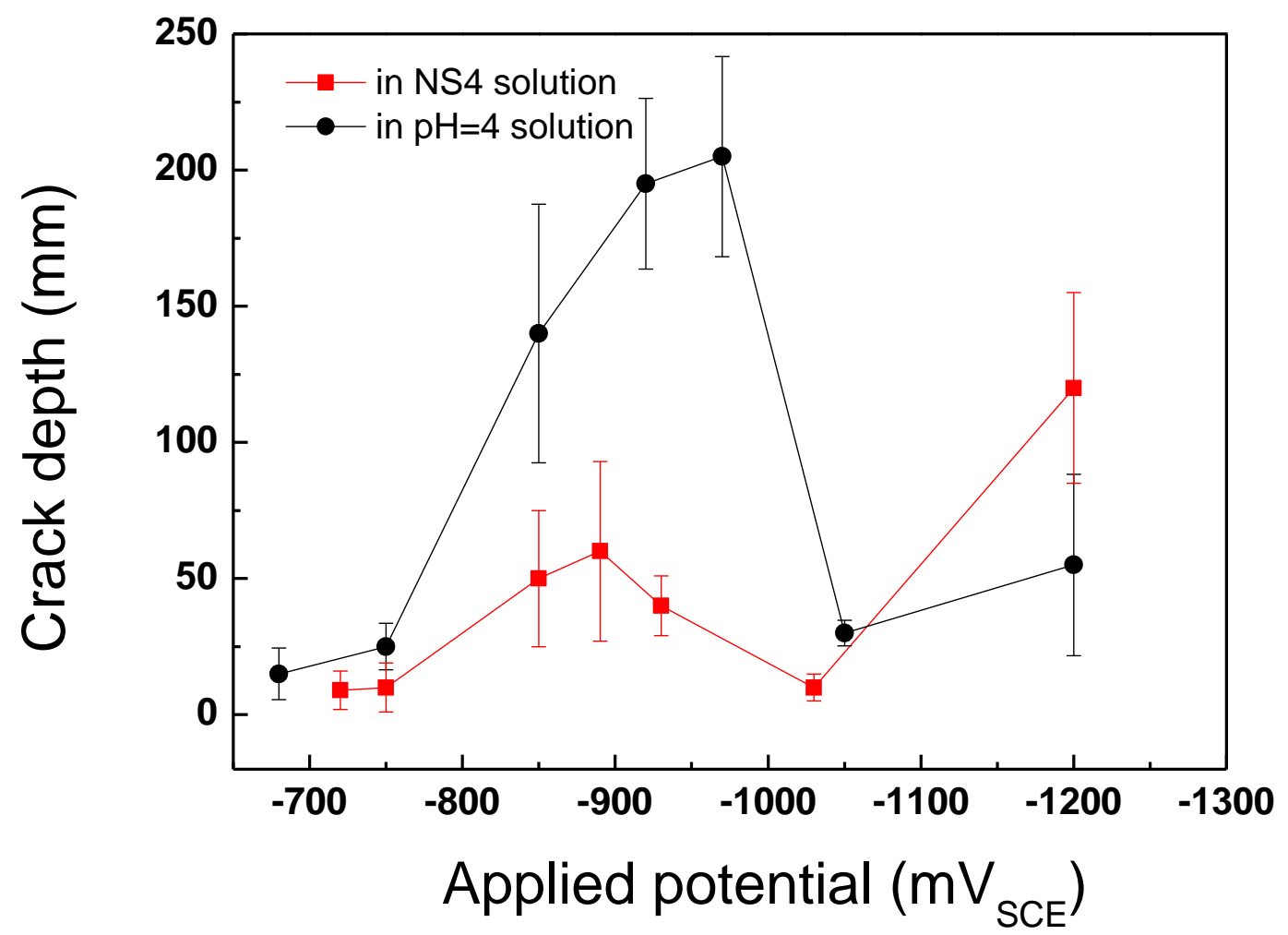

Fig.9.Statistic results of maximum crack depth at different potentials. 

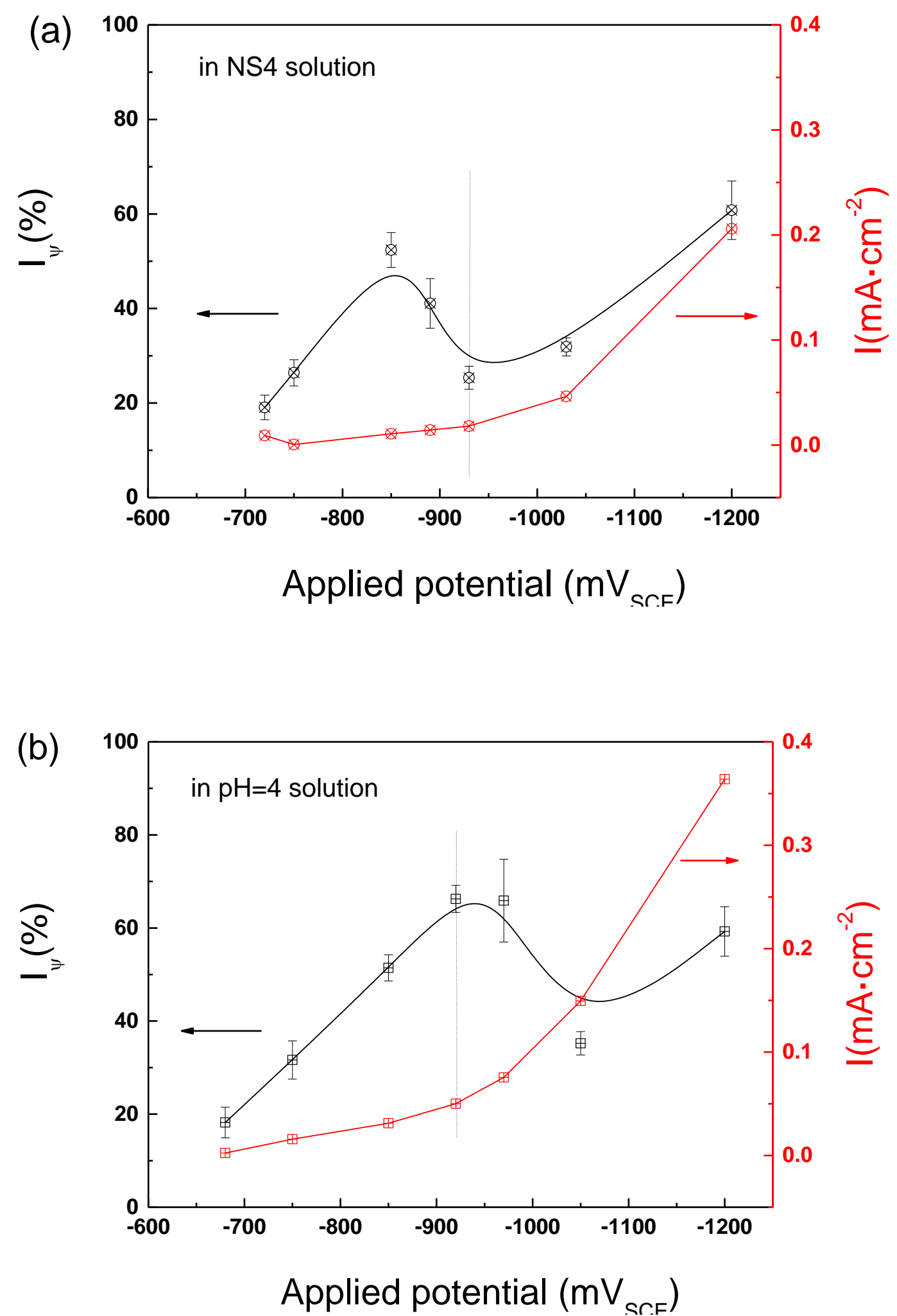

Fig.10. Dependence of reduction-in-area and cathodic current density obtained in NS4 solution (a) and $\mathrm{pH}=4$ solution (b) on the applied cathodic potentials. 

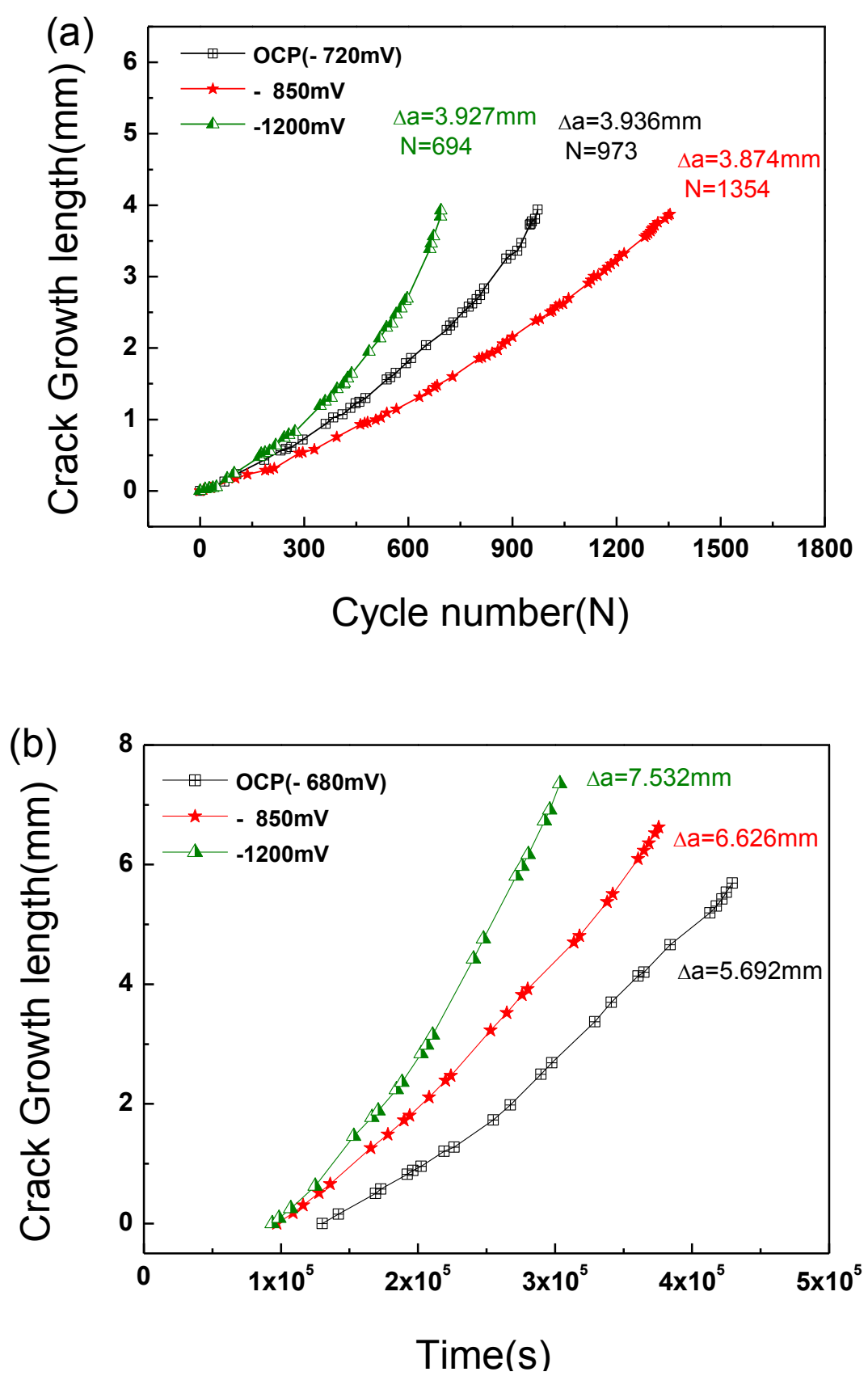

Fig.11.Crack growth behavior of pipeline steel in simulated soil environment, (a) CNT specimen under cycle loading in NS4 solution; (b) TPB specimen under continuous loading in a $\mathrm{pH}=4$ solution. 
Table caption

Table 1. Chemical composition of the NS4 solution and the $\mathrm{pH}=4$ solution.

\begin{tabular}{ccccccccc}
\hline \multirow{2}{*}{ Solution } & \multicolumn{7}{c}{ Chemical composition (g/L) } \\
\cline { 2 - 8 } & $\mathrm{CaCl}_{2} \cdot 2 \mathrm{H}_{2} \mathrm{O}$ & $\mathrm{MgSO}_{4} \cdot 7 \mathrm{H}_{2} \mathrm{O}$ & $\mathrm{NaHCO}_{3}$ & $\mathrm{KCl}$ & $\mathrm{KNO}_{3}$ & $\mathrm{NaCl}$ & $\mathrm{Na}_{2} \mathrm{SO}_{4}$ & $\mathrm{CH}_{3} \mathrm{COOH}$ \\
\hline $\begin{array}{c}\text { Near-neutral } \\
\text { pH solution } \\
\begin{array}{c}\text { Acidic } \\
\text { solution }\end{array}\end{array}$ & 0.181 & 0.131 & 0.122 & 0.483 & - & - & - & - \\
\hline
\end{tabular}

